\title{
Media Pluralism: what matters for governance and regulation?
}

Henry Allen, Sara Connolly and Shaun P. Hargreaves Heap *

\author{
*Respectively Research Associate at the Centre for Competition Policy, \\ University of East Anglia, Norwich NR4 7TJ, Professor in Economics at the \\ Norwich Business School, University of East Anglia and Professor of Political \\ Economy at King's College London.
}

Corresponding Author: Shaun P. Hargreaves Heap, Department of Political Economy, King's College London, The Strand, London WC1. Email s.hargreavesheap@kcl.ac.uk

Telephone 0044 (0)207848 1689

This work was supported by the ESRC Centre for Competition Policy at the University of East Anglia

\begin{abstract}
Media pluralism is valued in most jurisdictions because it contributes to a wellinformed citizenry. We examine what media policy and regulatory levers appear to affect five types of citizen knowledge across the EU. We conclude that concentration of titles matters more than ownership in newsprint; and that neither type of concentration matters in broadcasting in the same way, but the regulatory regime for public service broadcasting does, particularly for political knowledge.
\end{abstract}

Key words: media pluralism, citizen knowledge, regulation, concentration, public service broadcasting. 
The European Union is committed to protecting media pluralism as an essential pillar of the right to information and freedom of expression enshrined in Article 11 of the Charter of Fundamental Rights.....Ensuring Media pluralism, in our understanding, implies all measures that ensure citizens' access to a variety of information sources, opinion, voices, etc, in order to form their opinion without the undue influence of one dominant opinion forming power (Commission of the European Communities, 2007, p.4$5)$.

\section{Introduction}

Media pluralism is valued in most jurisdictions. ${ }^{1}$ The European Commission gives two widely shared reasons for this when describing it is 'an essential pillar in the right to information and freedom of expression' in the quotation above. We focus in this paper on the relation between media pluralism and 'the right to information' because an informed citizenry is important for the functioning of democracy. Pluralism matters in this context, as the second part of the quote suggests, because individuals can only reliably be thought to hold informed opinions if they have been exposed to the variety of possible views on a subject. ${ }^{2}$ The difficulty that often arises for policy makers and regulators in safeguarding media pluralism for this purpose is how to measure pluralism so as to know when it is threatened and therefore how to support an informed citizenry. In this paper, we address the policy makers' and regulators' difficulty in a new way.

Several studies and expert working groups over the years have been concerned with how to measure media pluralism. While they have helpfully identified a range of difficult issues for policy makers and regulators, the difficulties remain largely unresolved (see recent discussion by the Council of Europe, 2009, the European

\footnotetext{
${ }^{1}$ It was, for example, cited as the reason for the intervention by the Secretary of State for Culture, Media and Sport when requesting OFCOM to report on the proposed purchase of BSkyB by News International (OFCOM, 2010).

${ }^{2}$ This in turn is typically underpinned by two famous arguments. One is the dynamic argument that is often traced back to Milton (1644) in Areopagitica: 'Let her (Truth) and Falsehood grapple; whoever knew Truth put to the worse, in a free and open encounter?'. The other is static and arises from the 'wisdom of crowds' property that is directly related to the variety of views within the crowd (see Page, 2007).
} 
Commission, 2007, and OFCOM, 2010). For example, there are several key questions about how 'voices' in the media translate into 'views'. Should each owner of titles/channels count as a separate voice' in newsprint/broadcasting for this purpose? Or should each title/channel be treated as a separate 'voice' (even when owned by the same company)? Should the measure of variety involve counting the number of distinct 'voices' because access/availability is what matters? Or should each 'voice' be weighted by use? If the latter, should the Herfindahl-Hirschman Index (HHI) or some other be used, like the Entropy Index? Should 'voices' in different media be counted equally in any measure? There are typically good arguments on both sides of these issues that have stymied attempts at producing a measure of pluralism to guide policy.

Our approach is initially to sidestep the question of how to measure pluralism itself. Instead, we focus on whether there is cross-country evidence that the actual policy levers available to regulators and policy makers (which necessarily impinge on media pluralism in one way or another) affect what people know. The principal policy levers in all European jurisdictions are: the ability to affect the level of concentration in newsprint and broadcasting by blocking (or unwinding) media mergers, the public service broadcasting regime and, historically at least, the ease of access to the internet. We examine whether there is evidence from the cross-country experience of the EU to suggest that these levers have an effect citizen knowledge. Specifically, are differences in citizen knowledge associated with differences in these policies?

The advantage of focusing on this question is that we go directly to the policy makers and regulators concern with what policy levers can be used to advance the objective of an informed citizenry without first having to resolve the tricky issue of how to measure media pluralism. Of course, our findings on the levers that are associated with citizen knowledge have implications for how media pluralism should be measured to support an informed citizenry. However, since media pluralism may be valued for other reasons (e.g. freedom of expression), this need not be the only relevant way of measuring media pluralism. Nevertheless, it is interesting that our results are in some respects in conflict with the conventional wisdom (e.g. that of OFCOM, 2010) on how to measure pluralism. In particular, we find that 'voice' is better associated with 'titles' than owners in newspapers and the broadcasting market 
cannot be simply aggregated with the newsprint market because the distinction between 'internal' pluralism in broadcasting and the 'external' variety in newsprint remains important.

In the next section, we outline the key unresolved issues that currently complicate the conduct of policy/regulation and explain how we address them. Section 3 then describes our data sources: the measures of citizen knowledge across the EU and the policy levers that we assess. Section 4 presents and discusses the econometric results on the link between these policy and regulatory levers and our measures of different types of citizen knowledge. We conclude that policy/regulation should primarily be directed at avoiding concentration as measured by the HHI for titles in newsprint and self regulation in broadcasting.

\section{Issues}

In this section we set out the key open questions that have made policy in this area difficult; and we explain how we address them through the choice of possible policy explanatory variables in cross-country regressions on citizen knowledge. The section concludes with a brief discussion of the econometric issues in identifying the contribution of the media. This draws, in part, on the existing literature on the determinants of citizen knowledge and so also helps provide a wider context for our results.

Should 'voices' be simply counted or weighted by readership/audience?

Some jurisdictions, like the US, frame media merger rules in terms of the number of 'voices' in a market. The US view is based on the Federal Communication Commission argument that it is access to and not the use of different views that matters (see, Kwerel et al, 2002, and Besley and Prat, 2006, for a different approach that also makes numbers matter). In contrast, the typical EU rule weights 'voice' by readership/audience in a manner analogous to competition studies so as to avoid individual media outlets coming to dominate the market (as in rules that specify that market shares cannot exceed $x \%$ ).

We explore both possibilities by allowing for either the number of 'voices' or their number weighted by readership/audience to affect citizen knowledge in our 
regressions. There are a variety of possible weighting schemes for this purpose (see Council of Europe, 2009). We use the Herfindhal-Hirschman Index (HHI). In part this is pragmatic because of its prominence in competition studies. But it is also because there is a good theoretical reason for its use in this context that is typically not known (or recognized) in the literature on media pluralism. In so far as diversity is valued because it is the engagement between different views that is crucial for citizen knowledge, then the chances of any two random encounters in a population involving people who have read/seen different media sources becomes important. This probability is given by (1-HHI): that is, in so far as $\mathrm{HHI}$ increases and competition falls, so does the probability of an engagement of views in any random meeting of people.

Is a 'voice' an owner or an outlet?

Whether to treat owners or titles/channels as the unit for a 'voice' depends in part on the editorial freedom that is granted to titles/channels by their owners. Again, there are arguments on both sides. Some owners, for instance, are known to hold strong political views and so it may be sensible to take owners as the unit for a 'voice'. This may also be appropriate if the potential for bias comes from possible control of the media by government (see Besley and Prat, 2006). But, on the other hand, strict profit maximization may count against the adoption of these views across all the titles/channels/sites that he or she owns. Against this, it is sometimes argued that the pressure for profit maximization is weaker in these industries because the prevalence of private ownership structures insulates owners from the normal pressures in this direction from capital markets (see Djankov et al, 2003). Nevertheless, even when profit considerations predominate, the effect of concentration in ownership on product variety is itself a theoretically open question (see Berry and Waldfogel, 2001) and so requires empirical determination. With such contrasting considerations, we test for the influence of both owners and outlets and countenance the possibility that increased concentration could be beneficial. Specifically, we allow for either 'voice' as an outlet or 'voice' as owner in our regressions to see which in practice seems to matter, and in what way, for citizen knowledge.

Is media pluralism only important for political views? 
It is natural because of the well-known political views of some owners for attention to be focused on the pluralism of political views in the media (e.g. see European Commission, 2007, and OFCOM, 2012). However, the functioning of democracies depends on citizen knowledge more broadly and some other types of knowledge might also be affected by pluralism. Owners, for instance, could have distinct views that they might wish to promulgate in relation to matters in social policy or issues like global warming where the science or social science is in some degree unresolved. It is less clear that owners could sensibly have views in this sense over matters of pure scientific or economic knowledge. But they could have views over whether their outlets should cover news in relation to unemployment, inflation and the like, particularly when such news might have political consequences. ${ }^{3}$ Hence, it is possible where competitive pressures are sufficiently weak to give rein to these considerations (or that the 'inform and educate' objective of public broadcasters, see the next section, is sufficiently strong) that other categories of knowledge depend on media pluralism too. We test for this by running regressions for a range of types of knowledge: political, economic, scientific, technological and environmental.

\section{Is there a single market across different media for news and current affairs (and other} genres)?

Two issues are nested in this question: whether the 'external' pluralism of newsprint can be combined with the 'internal' pluralism of broadcasting and how to treat the medium of the internet.

Broadcasting has been subject in most jurisdictions to a variety of Public Service Broadcasting regulations (see Betzel, 2003). Crucially, for our purpose, they require versions of 'balance and impartiality' in news and current affairs (see for example Hanretty, 2012). This generates a form of 'internal' pluralism: that is, a variety of views are represented within each broadcasting outlet. In contrast, newsprint industries are not subject to such a requirement and outlets have more typically become identified with a particular 'view' with the result that pluralism is 'external' to the outlet and arises from the variety of views across all outlets in the market. The internet brings together in one medium both types as there are newsprint and

\footnotetext{
${ }^{3}$ See, for example, Soroka, 2006, on the asymmetric influence of economic news.
} 
broadcasting sites as well as many others, like blogs, that disseminate views. The question, therefore, naturally arises as to how to combine the internal pluralism of broadcasting with the external pluralism of newsprint and other internet sites when assessing how much pluralism exists overall in any jurisdiction.

At one extreme on this question, it can be argued that PSB is in retreat and profit or audience share (when the broadcaster depends on public subsidy) increasingly determine broadcasting behaviour. The difference between broadcasting and newsprint is, therefore, eroding in this respect and consequently, broadcasting outlets should increasingly be treated as voices in the same way as newsprint (and other internet sites). This might also explain why some jurisdictions have had specific cross media prohibitions. This, in effect, was the approach taken by OFCOM (2010) in its recent report on the public interest of News International purchasing BSkyB in the UK. They were un-persuaded by the argument, made by News International, for instance, that pluralism would be unaffected by the merger because BSkyB would still be governed by the PSB requirements for internal pluralism. Instead, OFCOM discussed various ways of weighting broadcasting voices with newsprint voices in order to arrive at an overall assessment of pluralism of voice in a single market for 'news' in the UK, albeit controversially (see Elstein, 2011).

In so far as the argument about the erosion of distinct PSB is correct, we expect to find that concentration in both newsprint and broadcasting matter in our citizen knowledge regressions; and if this is the case, then the respective size of the coefficients on these concentration variables indicates how each part of the media market should be weighted in such a measure of overall concentration (and so help resolve the conflict between Elstein. 2011, and OFCOM, 2010, on this).

At the other extreme, however, there is the argument that PSB still makes broadcasting different. The internal pluralism of each broadcaster does not supply a 'voice' that can be counted in the same way as the distinct 'voice' of a newspaper. In this case, the contribution of broadcasting to citizen knowledge does not come through its contribution to the single market in 'voices' formed with newsprint (and there would be no obvious reason for cross-media restrictions). If this were the case, then we would not expect concentration in broadcasting to matter in the citizen 
knowledge regressions. Instead, broadcasting would make a contribution through the strength of the PSB regime in promoting 'balance and impartiality'. There is evidence that the type of regulation (whether 'independent', 'self regulation' or 'ministerial regulation') is the most important sources of difference in the PSB regime for the trust in broadcasting across EU (see Connolly and Hargreaves Heap, 2007). Accordingly, we introduce these terms into the regressions on citizen knowledge to see whether broadcasting has an influence that depends on the PSB regime (and not just, as in the first argument, through a possible effect on combined concentration of 'voices' in a putative single market formed by broadcasting and newsprint). These terms might also plausibly capture the extent to which PSB contributes to citizen knowledge through other (non-pluralism related) objectives like the broad 'inform and educate' type objectives that are set for all PSBers and which may be more important in some knowledge types, like science, than pluralism per se.

The internet is an important source of information and so it would seem natural to include access to internet sites in the citizen knowledge regressions. However, the most frequently visited internet sites for current affairs are typically those of newspapers and broadcasters and so while the internet is an increasingly important

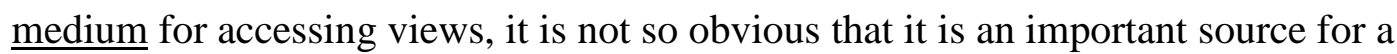
different set of opinions to those found in the conventional media. Indeed, there is evidence from the US that although the reliance on the internet has grown powerfully, it has not been associated with any increase in citizen knowledge (see Pew, 2007) and this is plausibly explained by the way that internet changes the medium used but not the actual views accessed. If there was comparable cross-country evidence on the concentration of 'hits' across sites on the internet, then one might test for this to see whether concentration here has an independent influence on citizen knowledge. Unfortunately there is not; there is only data on household access to the internet. In these circumstance, the inclusion of a separate explanatory variable of internet access risks a form of double counting that can weaken the econometric estimation of citizen knowledge and so we have not done so. ${ }^{4}$

\footnotetext{
${ }^{4}$ Indeed this is what we found. When we introduced internet access as a separate determinant of citizen knowledge, the significance of the newsprint and broadcasting variables diminished greatly. Further the size of the coefficient on the internet term
} 


\section{Econometric identification of media influence}

With little change in media ownership and concentration over time, it would be difficult to identify any relationship between this and citizen knowledge using time series techniques. Consequently, we focus on the cross country evidence regarding the apparent effect of such differences. Two issues arise.

First, by running cross-country regressions where a relationship between citizen knowledge and aspects of the media are identified, there is always a risk that the relationship is spurious or endogenously determined in the sense that it arises because both citizen knowledge and these media features are affected by some other set of independent variable(s). To counter this, we include a range of plausible independent variables to control for this possibility. There are other studies of citizen knowledge (which we discuss in more detail below) and they typically use education and per capita income levels as control variables for this purpose in what are similar regressions. We follow this example in all our regressions since both variables might plausibly affect all kinds of citizen knowledge that we examine. In addition, we introduce further controls in the regressions that are specific to the type of citizen knowledge. For example, in the models exploring political knowledge of central government there is both the possibility that in countries where regional governance is more important that citizens are generally less well-informed about central government or that media is structured differently with greater emphasis on regional newspapers or television channels. In either case, a model which fails to control for the importance of regional governance is liable to suffer from omitted bias. Therefore, we control for the constitutional importance in each country of regional as opposed to central government (see the next section for the full details of the regression equations in this and other respects).

Second, there is a question regarding the precise specification of this cross country relationship to test. This arises in part because the existing evidence on media occurred. 
influence points to a variety of possible specifications. We turn to this evidence now to bring out these choices and to put our study in context; and we conclude this subsection by explaining our strategy for dealing with multiple possible specifications.

The evidence on the influence of the media in these other studies is usually restricted to a small sample of countries and deals only with one aspect of citizen knowledge: some form of political knowledge. For example, Leeson (2008) considers knowledge of EU institutions among individuals in 9 candidate EU member countries in 2003 and he finds that the Freedom House Index (FHI) for each country is significant as is per capita income and education levels. Individual political apathy is apparently affected similarly in these countries. It is, however, difficult to develop any clear policy insights from this result on the effect of the media system both because the analysis turns on the FHI and, as Leeson acknowledges, this is only a 9 country study. The FHI index is problematic because it is derived from an assessment across three dimensions of a country (its legal, political and economic environment) and so it is not obvious how to associate variations in this index with specific differences in the media system that are amenable to policy change. In our empirical work, we directly address these weaknesses. We extend the country sample to the 27 EU countries; we consider whether the FHI is an adequate descriptor for the media system influence on citizen knowledge by comparing its performance with more disaggregated indicators (like the PSB regime, the HHIs and number counts, etc, mentioned earlier); and we consider not only political knowledge but also economic, scientific, technological and environmental knowledge.

There are also several studies that have considered whether public broadcasting has a special influence on citizen knowledge or on the knowledge of particular groups of citizens. The evidence is mixed but it is nevertheless suggestive of factors that we should consider including in our regressions. For instance, Soroka et al (2013) in a 6 country study finds that in 4 countries there is a gap between the knowledge of those who rely on public broadcasters as compared with commercial ones. Curran et al (2009) finds similarly that there is a big difference in knowledge between 3 European countries where public broadcasting plays a significant role and the US where it does not, but that this is largely accounted for by difference in knowledge among the less 
educated in Europe and the US. It would seem perhaps that public broadcasting matters most for the least well educated. Prat and Stromberg (2006), however, appear to find the contrary in Sweden because commercial television seems to cater well for low information citizens. Toka and Popescu (2009), in a cross EU study, find an even more complicated relation. They report that it is the less interested citizens who are affected by exposure to news programmes and while public broadcasters can be more influential than private ones, this depends on the degree of press freedom and internal pluralism. In short, the particular contribution of public broadcasting is contested.

Whilst theory provides some guidance for the specification of the model, some uncertainty over the precise specification - especially when capturing the context across the different types of knowledge remains. We therefore utilize Bayesian Model Averaging (BMA), this approach defines a focus regression with the variables that theory indicates should be included and an auxiliary regression containing those variables where there is uncertainty either in terms of theoretical rational or functional form. The BMA estimator takes account of the uncertainty and the resulting estimates are weighted averages based on all possible models, where the weights reflect the marginal likelihoods (De Luca and Magnus, 2011). Our focus regression is the same for each type of citizen knowledge. It contains the policy levers (measures of concentration in newsprint and broadcasting and the broadcasting regulatory system) and the shared control variables of GDP per capita and a measure of educational attainment (proportion of the population with secondary education). The auxiliary regressions contain knowledge specific controls and the contested influences of cross media ownership and the interactions between the PSBshare/PSB regulation and the education levels. We use the BMA estimator in Stata v14, this estimates coefficients, t-statistics and posterior probabilities (pip) - as a rule of thumb, a variable in the auxiliary equation is considered to be significant when the absolute value of the tstatistic is greater than 1 or the pip is greater than 0.5 (De Luca and Magnus, 2011).

\section{Data}

Our data on citizen knowledge come from the European Election Survey 2009 and Eurobarometer surveys taken between 2007-9 (see Appendix 1). The data is collected 
at the individual level and we use the country average in our cross-country regressions. The precise questions are as follows. We make no claim that any individual question unambiguously captures a particular type of knowledge. We claim only that across the board they do convey a picture of country level differences in these categories of knowledge.

The election survey asked questions that tested knowledge of EU and domestic politics. We focus on domestic politics because knowledge of the EU and its institutions is plausibly affected by attitudes to Europe and the EU which are not the same across countries and are unrelated to the media system. There were 3 standardized questions on domestic politics. They ask each respondent to decide whether the following statements are true or false: the identity of the Minister for Children (or its analogue in that country) is....; the minimum age for membership of the governing Assembly of that country is.....; the number of seats in the governing Assembly for that country is...... Our variable is the proportion of correct answers for each country and it ranges from $36 \%$ in Romania to $77 \%$ in Denmark. Since these questions refer to knowledge of central government, our auxiliary equation control variable in this knowledge regression equation is the extent of regional government in each country, as identified by Hooghe et al (2010). In addition, while the specific mechanisms are unclear to us, there may be some general influence from geography over citizen political knowledge and so we also have two geography controls in this auxiliary equation: EU East and EU South.

The Eurobarometer regularly surveys economic knowledge by asking citizens of the EU what are the current rates of growth, inflation and unemployment in their country. These are compared with the correct values for each country in these surveys and we use the associated variable: the proportion of correct answers for each country, these vary from 5\% in Romania to $30 \%$ in Slovakia. Since individuals may be more or less attuned to news on an economic variable when it has recently been high/low or the structure of the relevant media market itself be altered by the recent economic environment, our auxiliary regression control variables for this type of knowledge are the behaviour of the economic variables over the period 2001-06 (data taken from Eurostat). 
The Eurobarometer also asks at less regular intervals 10 questions on scientific knowledge like whether electrons are bigger than atoms, the sun goes round the earth, and so on. The proportion of correct answers in this category ranges from $48 \%$ in Bulgaria to $79 \%$ in Sweden. We expect that a population with more extensive scientific education or a society which places greater value on science and technology will perform better on these questions and so our auxiliary equation control variable for this type of knowledge is the proportion of the population with tertiary education in STEM subjects.

Knowledge in these 3 categories is 'objective' in the sense that we judge knowledge by the proportion of right answers to questions. We have two further 'subjective' knowledge variables. They are knowledge variables because they refer to aspects of the world where the accuracy of individual views could be tested in the same way, but they are 'subjective' because we rely on the individuals' own assessment of how well they know about them. The first is knowledge of new technologies: we report on the proportion who have 'heard of' either nanotechnology and/or GM and/or animal cloning and/or synthetic biology and/or biobanks. This ranges from 33\% in Malta to $70 \%$ in Sweden. We again use the tertiary education in STEM subjects as the additional possible knowledge specific control in its auxiliary equation. The second is how well, informed people feel about climate change. The answers for those who feel well informed range respectively from $29 \%$ in Portugal to $84 \%$ in Sweden and from $41 \%$ in Estonia to $80 \%$ in Sweden. Country knowledge of climate change may be sensitive to their relative contribution to or efforts to control the problem, therefore we use Green House Gas emissions per capita as the possible additional a control (2001-06 from Eurostat) in the auxiliary equation for this knowledge variable.

The data on channels and newspapers and PSB shares comes from the European Commission $^{5}$ and the PSB regulatory regime is distinguished by whether and in what way the regulator is independent and comes from Betzel (2003). These distinctions turn on formal differences but there is evidence that such differences are useful

\footnotetext{
${ }^{5}$ European Commission, 2007. The data is the 10 largest - in terms of audience or circulation share. Whilst, in some instances, there may be more than 10 titles or channels, the audience or circulation share is so small that this has no material impact upon the measures of concentration.
} 
predictors of actual independence (see Hanretty and Koop, 2013). Education and per capita income variables come from Eurostat.

\section{Results and Discussion}

We estimate the following generic citizen knowledge (CK) equation.

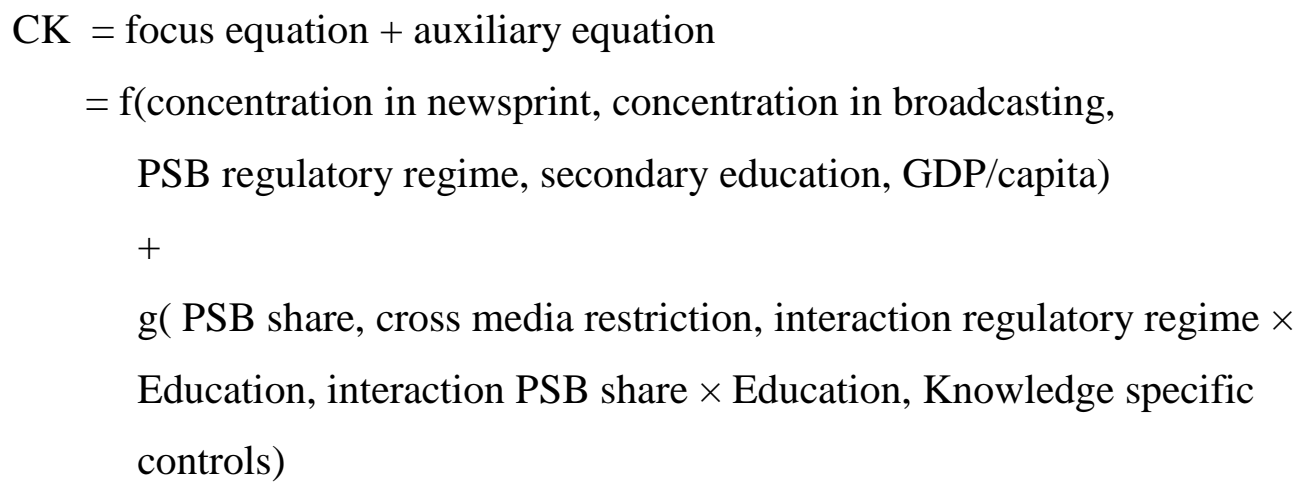

Following from the earlier discussion we consider a variety of possible measures of concentration in newsprint and broadcasting in the focus equation for each type of knowledge.

i) Freedom House Index (FHI) or

ii) HHI for owners of channels and HHI for owners of titles or

iii) $\mathrm{HHI}$ for channels and $\mathrm{HHI}$ for titles or

iv) number of owners of channels and number of owners of titles or

v) number of channels and number of titles

The 'PSB regulatory regime is in the focus equation. We are less sure of the claim that the PSB share or that the interactions of either PSB variable with education levels matter and so they are included in the auxiliary equation. Between them they test for a distinct and separate influence from 'internal' pluralism. The cross media restriction is another policy lever. It is a dummy taking a value of 1 when there is cross media ownership. Again we are less sure, given the earlier discussion, whether to expect that it is influential and so it appears in the auxiliary equation. 
The results for each type of knowledge are summarized in Tables 1-5. A separate BMA equation is estimated with each possible measure of concentration in newsprint and broadcasting. Each column title takes its name from this choice. We begin by noting that the control variables in the focus equation are often significant and have the expected signs; and some of the knowledge specific controls in the auxiliary equations are also significant and have the expected signs. 
Table 1: Political knowledge (BMA models)

\begin{tabular}{|c|c|c|c|c|c|c|c|c|c|c|c|c|c|c|c|}
\hline \multirow[b]{3}{*}{ Constant } & \multicolumn{3}{|c|}{ HHI Outlets } & \multicolumn{3}{|c|}{ HHI Owners } & \multicolumn{3}{|c|}{ No Outlets } & \multicolumn{3}{|c|}{ No Owners } & \multicolumn{3}{|c|}{ FHI } \\
\hline & Coef. & $\mathrm{t}$ & pip & Coef. & $\mathrm{t}$ & pip & Coef. & $\mathrm{t}$ & pip & Coef. & $\mathrm{t}$ & pip & Coef. & $\mathrm{t}$ & pip \\
\hline & -43.81 & -0.65 & 1 & -77.37 & -1.02 & 1 & -62.87 & -0.67 & 1 & -108.05 & -1.3 & 1 & 59.80 & 3.99 & 1 \\
\hline Freedom House Index & & & & & & & & & & & & & -0.60 & -2.01 & 1 \\
\hline HHI channels & 0.00 & 0.18 & 1 & & & & & & & & & & & & \\
\hline HHI news titles & -0.01 & -1.83 & 1 & & & & & & & & & & & & \\
\hline HHI broadcasters & & & & 0.00 & -0.21 & 1 & & & & & & & & & \\
\hline HHI newspaper owners & & & & 0.00 & -0.59 & 1 & & & & & & & & & \\
\hline Number of TV channels & & & & & & & 0.10 & 0.09 & 1 & & & & & & \\
\hline Number of newspapers & & & & & & & 0.57 & 0.34 & 1 & & & & & & \\
\hline Number of broadcasters & & & & & & & & & & 0.98 & 0.75 & 1 & & & \\
\hline Number of newspaper owners & & & & & & & & & & -0.64 & -0.46 & 1 & & & \\
\hline PSB regulatory authority & 101.96 & 1.44 & 1 & 124.23 & 1.61 & 1 & 102.50 & 1.13 & 1 & 147.73 & 1.82 & 1 & & & \\
\hline PSB regulated by ministry & 86.85 & 1.16 & 1 & 118.76 & 1.52 & 1 & 96.85 & 0.95 & 1 & 149.67 & 1.71 & 1 & & & \\
\hline PSB audience share & -0.05 & -0.26 & 1 & 0.10 & 0.47 & 1 & 0.06 & 0.36 & 1 & 0.10 & 0.62 & 1 & -0.05 & -0.32 & 1 \\
\hline GDP per capita & 0.00 & 1.3 & 1 & 0.00 & 0.28 & 1 & 0.00 & 0.08 & 1 & 0.00 & -0.42 & 1 & 0.00 & 0.15 & 1 \\
\hline $\begin{array}{l}\% \text { of population with Secondary education } \\
\text { Auxiliary }\end{array}$ & 1.43 & 1.48 & 1 & 1.85 & 1.78 & 1 & 1.54 & 1.1 & 1 & 2.24 & 1.93 & 1 & 0.16 & 1.07 & 1 \\
\hline Interaction: PSB Regulator with Education & -1.31 & -1.43 & 0.81 & -1.53 & -1.57 & 0.8 & -1.27 & -1.11 & 0.7 & -1.86 & -1.74 & 0.83 & & & \\
\hline Interaction: PSB Ministry with Education & -1.11 & -1.16 & 0.72 & -1.45 & -1.49 & 0.78 & -1.20 & -0.93 & 0.62 & -1.88 & -1.66 & 0.82 & & & \\
\hline Cross media & 2.66 & 0.62 & 0.4 & 5.85 & 1.08 & 0.65 & 5.24 & 0.91 & 0.56 & 8.46 & 1.45 & 0.77 & & & \\
\hline Regional Governance index & -0.74 & -1.58 & 0.82 & -1.01 & -2.03 & 0.88 & -0.88 & -1.6 & 0.84 & -1.06 & -2.47 & 0.92 & -0.22 & -0.81 & 0.52 \\
\hline EU East & -6.98 & -0.73 & 0.47 & -14.73 & -1.32 & 0.74 & -13.36 & -1.03 & 0.62 & -15.74 & -1.51 & 0.8 & -2.40 & -0.41 & 0.28 \\
\hline EU South & 0.23 & 0.09 & 0.15 & -0.14 & -0.05 & 0.15 & -0.04 & -0.02 & 0.14 & 0.47 & 0.14 & 0.16 & 0.82 & 0.23 & 0.19 \\
\hline
\end{tabular}


Table 2: Economic knowledge (BMA models)

\begin{tabular}{|c|c|c|c|c|c|c|c|c|c|c|c|c|c|c|c|}
\hline \multirow[b]{3}{*}{ Constant } & \multicolumn{3}{|c|}{ HHI outlets } & \multicolumn{3}{|c|}{ HHI owners } & \multicolumn{3}{|c|}{ No outlets } & \multicolumn{3}{|c|}{ No owners } & \multicolumn{3}{|c|}{ FHI } \\
\hline & Coef. & $\mathrm{t}$ & pip & Coef. & $\mathrm{t}$ & pip & Coef. & $\mathrm{t}$ & pip & Coef. & $\mathrm{t}$ & pip & Coef. & $\mathrm{t}$ & pip \\
\hline & -11.99 & -0.73 & 1 & -8.67 & -0.63 & 1 & -9.04 & -0.63 & 1 & -6.94 & -0.51 & 1 & -0.04 & 0 & 1 \\
\hline Freedom House Index & & & & & & & & & & & & & -0.19 & -1 & 1 \\
\hline HHI channels & 0.00 & 0.63 & 1 & & & & & & & & & & & & \\
\hline HHI news titles & 0.00 & -0.83 & 1 & & & & & & & & & & & & \\
\hline HHI broadcasters & & & & 0.00 & -0.21 & 1 & & & & & & & & & \\
\hline Number of TV channels & & & & & & & -0.38 & -0.66 & 1 & & & & & & \\
\hline Number of newspapers & & & & & & & 0.16 & 0.18 & 1 & & & & & & \\
\hline Number of broadcasters & & & & & & & & & & -0.39 & -0.49 & 1 & & & \\
\hline Number of newspaper owners & & & & & & & & & & -0.29 & -0.33 & 1 & & & \\
\hline PSB regulatory authority & 5.70 & 0.46 & 1 & 3.07 & 0.29 & 1 & 4.22 & 0.39 & 1 & 2.91 & 0.27 & 1 & & & \\
\hline PSB regulated by ministry & 0.47 & 0.04 & 1 & 3.64 & 0.39 & 1 & 0.84 & 0.07 & 1 & 2.84 & 0.29 & 1 & & & \\
\hline GDP per capita & 0.00 & 1.89 & 1 & 0.00 & 1.18 & 1 & 0.00 & 1.63 & 1 & 0.00 & 1.5 & 1 & 0.00 & 0.86 & 1 \\
\hline $\begin{array}{l}\% \text { of population with Secondary education } \\
\text { Auxiliary }\end{array}$ & 0.23 & 1.52 & 1 & 0.24 & 1.65 & 1 & 0.20 & 1.28 & 1 & 0.23 & 1.63 & 1 & 0.17 & 2.28 & 1 \\
\hline Interaction: PSB Regulator with Education & -0.08 & -0.48 & 0.33 & -0.04 & -0.27 & 0.2 & -0.04 & -0.32 & 0.24 & -0.04 & -0.3 & 0.22 & & & \\
\hline Interaction: PSB Ministry with Education & 0.04 & 0.29 & 0.26 & 0.01 & 0.07 & 0.17 & 0.04 & 0.26 & 0.23 & 0.01 & 0.08 & 0.19 & & & \\
\hline Cross media & -0.87 & -0.4 & 0.25 & -0.71 & -0.36 & 0.23 & -0.52 & -0.32 & 0.21 & -0.54 & -0.32 & 0.21 & & & \\
\hline Average growth rate 2001/06 & -0.35 & -0.5 & 0.31 & -0.64 & -0.63 & 0.4 & -0.26 & -0.4 & 0.25 & -0.27 & -0.37 & 0.23 & -0.23 & -0.41 & 0.27 \\
\hline Average inflation rate $2001 / 06$ & -0.03 & -0.16 & 0.16 & -0.06 & -0.28 & 0.19 & -0.06 & -0.29 & 0.2 & -0.07 & -0.31 & 0.21 & -0.02 & -0.1 & 0.17 \\
\hline Average unemployment rate 2001/06 & 0.65 & 1.19 & 0.7 & 0.50 & 0.89 & 0.55 & 0.50 & 0.93 & 0.58 & 0.57 & 0.99 & 0.6 & 0.39 & 0.88 & 0.55 \\
\hline
\end{tabular}


Table 3: Science knowledge (BMA models)

\begin{tabular}{|c|c|c|c|c|c|c|c|c|c|c|c|c|c|c|c|}
\hline \multirow[b]{3}{*}{ Constant } & \multicolumn{3}{|c|}{ HHI outlets } & \multicolumn{3}{|c|}{ HHI owners } & \multicolumn{3}{|c|}{ No outlets } & \multicolumn{3}{|c|}{ No owners } & \multicolumn{3}{|c|}{ FHI } \\
\hline & Coef. & $\mathrm{t}$ & pip & Coef. & $\mathrm{t}$ & pip & Coef. & $\mathrm{t}$ & pip & Coef. & $\mathrm{t}$ & pip & Coef. & $\mathrm{t}$ & pip \\
\hline & -5.68 & -0.25 & 1 & 0.24 & 0.01 & 1 & 21.43 & 1.39 & 1 & 14.03 & 0.48 & 1 & 44.37 & 4.54 & 1 \\
\hline Freedom House Index & & & & & & & & & & & & & -0.44 & -2.1 & 1 \\
\hline HHI channels & 0.01 & 2.49 & 1 & & & & & & & & & & & & \\
\hline HHI news titles & 0.00 & -0.9 & 1 & & & & & & & & & & & & \\
\hline HHI broadcasters & & & & 0.00 & 1.8 & 1 & & & & & & & & & \\
\hline HHI newspaper owners & & & & 0.00 & 0.43 & 1 & & & & & & & & & \\
\hline Number of TV channels & & & & & & & -1.69 & -3.26 & 1 & & & & & & \\
\hline Number of newspapers & & & & & & & -0.51 & -0.63 & 1 & & & & & & \\
\hline Number of broadcasters & & & & & & & & & & -2.02 & -3.09 & 1 & & & \\
\hline Number of newspaper owners & & & & & & & & & & -1.09 & -1.59 & 1 & & & \\
\hline PSB regulatory authority & 20.15 & 0.97 & 1 & 16.87 & 0.67 & 1 & 13.98 & 1.07 & 1 & 25.25 & 0.86 & 1 & & & \\
\hline PSB regulated by ministry & 11.34 & 0.65 & 1 & 11.75 & 0.52 & 1 & 7.45 & 0.6 & 1 & 22.39 & 0.77 & 1 & & & \\
\hline PSB audience share & 0.18 & 1.53 & 1 & 0.11 & 0.74 & 1 & 0.29 & 2.77 & 1 & 0.17 & 1.99 & 1 & 0.14 & 1.38 & 1 \\
\hline GDP per capita & 0.00 & 4.22 & 1 & 0.00 & 2.35 & 1 & 0.00 & 4.76 & 1 & 0.00 & 4.43 & 1 & 0.00 & 1.79 & 1 \\
\hline $\begin{array}{l}\% \text { of population with Secondary education } \\
\text { Auxiliary }\end{array}$ & 0.44 & 1.78 & 1 & 0.41 & 1.33 & 1 & 0.33 & 1.9 & 1 & 0.56 & 1.47 & 1 & 0.23 & 2.98 & 1 \\
\hline Interaction: PSB Regulator with Education & -0.16 & -0.58 & 0.44 & -0.15 & -0.46 & 0.33 & -0.05 & -0.3 & 0.23 & -0.25 & -0.64 & 0.45 & & & \\
\hline Interaction: PSB Ministry with Education & -0.05 & -0.21 & 0.27 & -0.10 & -0.33 & 0.26 & -0.01 & -0.07 & 0.19 & -0.22 & -0.56 & 0.39 & & & \\
\hline Cross media & 5.51 & 1.41 & 0.77 & 5.01 & 1.27 & 0.73 & 4.74 & 1.39 & 0.77 & 3.71 & 1.31 & 0.74 & & & \\
\hline$\%$ of population with Tertiary education in STEM & 0.00 & -0.03 & 0.17 & 0.08 & 0.36 & 0.24 & 21.43 & 1.39 & 1 & 14.03 & 0.48 & 1 & 0.01 & 0.05 & 0.16 \\
\hline
\end{tabular}


Table 4: Heard about new technology (BMA models)

\begin{tabular}{|c|c|c|c|c|c|c|c|c|c|c|c|c|c|c|c|}
\hline \multirow[b]{3}{*}{ Constant } & \multicolumn{3}{|c|}{ HHI Outlets } & \multicolumn{3}{|c|}{ HHI Owners } & \multicolumn{3}{|c|}{ No Outlets } & \multicolumn{3}{|c|}{ No owners } & \multicolumn{3}{|c|}{ FHI } \\
\hline & Coef. & $\mathrm{t}$ & pip & Coef. & $\mathrm{t}$ & pip & Coef. & $\mathrm{t}$ & pip & Coef. & $\mathrm{t}$ & pip & Coef. & $\mathrm{t}$ & pip \\
\hline & 12.90 & 0.44 & 1 & 2.56 & 0.08 & 1 & 15.66 & 0.96 & 1 & 14.43 & 0.87 & 1 & 31.06 & 3.08 & 1 \\
\hline Freedom House Index & & & & & & & & & & & & & -0.34 & -1.58 & 1 \\
\hline HHI channels & 0.00 & 0.78 & 1 & & & & & & & & & & & & \\
\hline HHI news titles & -0.01 & -2.35 & 1 & & & & & & & & & & & & \\
\hline HHI broadcasters & & & & 0.00 & 0.86 & 1 & & & & & & & & & \\
\hline HHI newspaper owners & & & & 0.00 & -0.22 & 1 & & & & & & & & & \\
\hline Number of TV channels & & & & & & & -1.46 & -2.8 & 1 & & & & & & \\
\hline Number of newspapers & & & & & & & 1.06 & 1.26 & 1 & & & & & & \\
\hline Number of broadcasters & & & & & & & & & & -2.02 & -2.65 & 1 & & & \\
\hline Number of newspaper owners & & & & & & & & & & 1.04 & 1.24 & 1 & & & \\
\hline PSB regulatory authority & 18.11 & 0.61 & 1 & 15.80 & 0.5 & 1 & 10.02 & 0.67 & 1 & 8.04 & 0.56 & 1 & & & \\
\hline PSB regulated by ministry & 7.84 & 0.3 & 1 & 8.91 & 0.31 & 1 & -6.71 & -0.47 & 1 & -1.95 & -0.15 & 1 & & & \\
\hline PSB audience share & -0.12 & -1.07 & 1 & -0.08 & -0.5 & 1 & 0.01 & 0.14 & 1 & -0.03 & -0.24 & 1 & -0.02 & -0.2 & 1 \\
\hline GDP per capita & 0.00 & 4.32 & 1 & 0.00 & 2.29 & 1 & 0.00 & 4.79 & 1 & 0.00 & 4.09 & 1 & 0.00 & 2 & 1 \\
\hline $\begin{array}{l}\% \text { of population with Secondary education } \\
\text { Auxiliary }\end{array}$ & 0.51 & 1.44 & 1 & 0.49 & 1.27 & 1 & 0.27 & 1.44 & 1 & 0.34 & 1.92 & 1 & 0.28 & 3.52 & 1 \\
\hline Interaction: PSB Regulator with Education & -0.27 & -0.69 & 0.52 & -0.22 & -0.53 & 0.38 & -0.11 & -0.58 & 0.41 & -0.07 & -0.41 & 0.31 & & & \\
\hline Interaction: PSB Ministry with Education & -0.14 & -0.41 & 0.35 & -0.15 & -0.4 & 0.3 & 0.06 & 0.34 & 0.32 & 0.02 & 0.11 & 0.24 & & & \\
\hline Cross media & 1.86 & 0.62 & 0.4 & 4.30 & 1.06 & 0.64 & 3.27 & 1.02 & 0.62 & 2.08 & 0.7 & 0.45 & & & \\
\hline$\%$ of population with Tertiary education in STEM & -0.15 & -0.53 & 0.34 & 0.01 & 0.07 & 0.17 & 0.03 & 0.24 & 0.2 & 0.04 & 0.26 & 0.2 & 0.01 & 0.08 & 0.16 \\
\hline
\end{tabular}


Table 5: Climate change (BMA models)

\begin{tabular}{|c|c|c|c|c|c|c|c|c|c|c|c|c|c|c|c|}
\hline \multirow[b]{3}{*}{ Constant } & \multicolumn{3}{|c|}{ HHI outlets } & \multicolumn{3}{|c|}{ HHI owners } & \multicolumn{3}{|c|}{ No outlets } & \multicolumn{3}{|c|}{ No owners } & \multicolumn{3}{|c|}{ FHI } \\
\hline & Coef. & $\mathrm{t}$ & pip & Coef. & $\mathrm{t}$ & pip & Coef. & $\mathrm{t}$ & pip & Coef. & $\mathrm{t}$ & pip & Coef. & $\mathrm{t}$ & pip \\
\hline & 34.52 & 1.03 & 1 & 17.93 & 0.63 & 1 & 34.76 & 1.33 & 1 & 38.06 & 1.31 & 1 & 33.68 & 1.94 & 1 \\
\hline Freedom House Index & & & & & & & & & & & & & -0.68 & -1.83 & 1 \\
\hline HHI channels & 0.00 & 0.03 & 1 & & & & & & & & & & & & \\
\hline HHI news titles & -0.01 & -1.29 & 1 & & & & & & & & & & & & \\
\hline HHI broadcasters & & & & 0.00 & 0.49 & 1 & & & & & & & & & \\
\hline HHI newspaper owners & & & & 0.00 & 0.14 & 1 & & & & & & & & & \\
\hline Number of TV channels & & & & & & & -0.98 & -1.16 & 1 & & & & & & \\
\hline Number of newspapers & & & & & & & -1.74 & -1.18 & 1 & & & & & & \\
\hline Number of broadcasters & & & & & & & & & & -1.32 & -1.11 & 1 & & & \\
\hline Number of newspaper owners & & & & & & & & & & -0.92 & -0.71 & 1 & & & \\
\hline PSB regulatory authority & 9.41 & 0.33 & 1 & 8.37 & 0.3 & 1 & 5.55 & 0.25 & 1 & 3.45 & 0.13 & 1 & & & \\
\hline PSB regulated by ministry & -29.3 & -1.06 & 1 & -27.3 & -1.02 & 1 & -22.96 & -0.94 & 1 & -30.64 & -1.1 & 1 & & & \\
\hline PSB audience share & -0.05 & -0.26 & 1 & -0.02 & -0.08 & 1 & 0.10 & 0.57 & 1 & 0.00 & -0.02 & 1 & 0.11 & 0.61 & 1 \\
\hline $\begin{array}{l}\text { GDP per capita } \\
\% \text { of population with }\end{array}$ & 0.00 & 3.4 & 1 & 0.00 & 3.14 & 1 & 0.00 & 4.3 & 1 & 0.00 & 3.86 & 1 & 0.00 & 1.93 & 1 \\
\hline Secondary education & 0.32 & 0.93 & 1 & 0.37 & 1.11 & 1 & 0.43 & 1.38 & 1 & 0.35 & 1.05 & 1 & 0.27 & 1.84 & 1 \\
\hline $\begin{array}{l}\text { Auxiliary } \\
\text { Interaction: PSB Regulator } \\
\text { with Education } \\
\text { Interaction: PSB Ministry with }\end{array}$ & -0.25 & -0.69 & 0.47 & -0.22 & -0.64 & 0.44 & -0.14 & -0.49 & 0.38 & -0.17 & -0.51 & 0.42 & & & \\
\hline Education & 0.25 & 0.66 & 0.46 & 0.22 & 0.63 & 0.44 & 0.18 & 0.54 & 0.39 & 0.27 & 0.7 & 0.49 & & & \\
\hline $\begin{array}{l}\text { Cross media } \\
\% \text { of population with Tertiary }\end{array}$ & 5.48 & 0.89 & 0.56 & 9.84 & 1.67 & 0.84 & 11.54 & 2.19 & 0.92 & 8.66 & 1.57 & 0.82 & & & \\
\hline education in STEM & -0.08 & -0.26 & 0.2 & 0.02 & 0.08 & 0.17 & 0.03 & 0.13 & 0.17 & 0.02 & 0.12 & 0.17 & 0.03 & 0.12 & 0.17 \\
\hline GHG per capita & -1404 & -1.16 & 0.69 & -2201 & -2.04 & 0.9 & -2470 & -2.57 & 0.95 & -2300 & -2.46 & 0.94 & -799 & -0.75 & 0.48 \\
\hline
\end{tabular}


Like Leeson (2008) we find that the FHI is a useful predictor of citizen knowledge in each of our five categories (see the last column). The lower numbers in the FHI are associated with 'freer' countries and so the negative coefficient means that countries that are more free on this index have higher citizen knowledge. The difficulty with this index for our purpose, as noted above, is that there is no clear connection between it and the various possible media policy levers. When we drop the FHI variable and include specific aspects of the media landscape in these equations, we find that there is a media influence in all our five categories. Turning to the policy implications, we draw the following five conclusions concerning the influence of media policy levers.

1) An increase in concentration in newsprint titles, as measured by the HHI, reduces $\mathrm{CK}$ in two of the five categories (Political knowledge and New Technology).

2) There is no clear evidence that concentration of ownership in newsprint affects CK (Numbers of owners have a positive effect in New Technology, but a negative effect in Science).

3) An increase in concentration in broadcasting, measured by numbers of owners or titles, increases CK in two of the five categories (Science and New Technology).

4) There is evidence in one category (Politics) that an independent regulator for broadcasting improves CK.

5) Cross-media ownership does not harm $\mathrm{CK}$ in any category and it is associated with higher CK in four categories (Politics, Science Climate Change and New Technology).

The media policy lever results are reassuring in the sense that they accord with other results where there is overlap (e.g. PSB effects depend on the form of regulation and probably are more important for political knowledge when education levels are relatively low). They also appear, helpfully, to resolve issues where there are no clear a priori expectations. For example, concentration of titles matters more than owners 
in newsprint. Further, and, contrary to $\operatorname{OFCOM}(2010)$, TV and newsprint cannot be sensibly aggregated into a single market for 'voices'. This is because concentration in broadcasting tends to promote $\mathrm{CK}$ whereas concentration has a negative effect in newsprint. As a result the concentration levels cannot be added together to produce some overall or combined level of concentration. In other words, while the concept of external pluralism can be usefully applied to policy for newsprint, it cannot be in broadcasting.

The positive effect from concentration in broadcasting may, like the positive effect from cross-media ownership, seem a little surprising. But they may be related in the sense that both are picking up on aspects of the PSB regime which are important and explain why the TV and newsprint cannot be simply aggregated into a single market for 'voices'. Thus, one interpretation of 3) is that, ceteris paribus, concentration leads to larger broadcasters and large broadcasters are better able to invest in programming of a factual kind (i.e. an endogenous fixed cost argument). Alternatively, since this effect is apparent in Science, New Technology and Climate Change knowledge, it is perhaps more likely that these areas are intrinsically less popular areas and so become squeezed when competition is fiercer. Likewise, it is possible that the reason some countries allow cross-media ownership is that they have an effective form of PSB regulation in broadcasting and so can rely on forms of internal pluralism in broadcasting. In turn, this is why cross-media ownership has a positive effect on CK. Hence, cross-media ownership like concentration in broadcasting could be picking up on the way that broadcasting can make a distinctive contribution to $\mathrm{CK}$ via internal pluralism. A conclusion that is supported in part by 4 ).

There is perhaps one more result that deserves further comment: that titles seem to matter more than ownership when calculating concentration. This is perhaps surprising because the reverse is usually assumed by the authorities: e.g. see European Commission (2007) and OFCOM (2010 and 2012). Nevertheless, it is consistent with some evidence from studies in the US where it seems ownership matters less and market forces more than is often supposed (see also Gentzkow and Shapiro, 2006) and with the Berry and Waldfogel (2003) insight that concentration in ownership has ambiguous theoretical effects on diversity. It also fits with the evidence here that the influence of cross media ownership is weak. It tends, however, to count against the 
Besley and Prat (2006) argument with respect to the connection between ownership and bias that comes through potential government influence over the media. This is both because ownership seems less important than titles/channels and because the influence of the media on knowledge is not obviously concentrated on the more politically sensitive types of knowledge.

\section{Conclusion}

In this paper, we examine whether there is cross-country evidence in the EU to support the idea that policy makers and regulators can influence citizen knowledge through policy levers which affect media pluralism. There is. And it comes from a larger cross section of countries and involves a wider range of categories of citizen knowledge than has been considered before.

Further, our evidence clarifies what are the key policy levers. In this respect, the results address several important and unresolved debates in the literature. In particular, concentration in newsprint, particularly in relation to titles and as measured with the HHI, is typically associated negatively with citizen knowledge.

Concentration matters less apparently in broadcasting and where it does, it is positively associated with citizen knowledge. This means that it is not sensible to treat newsprint and broadcasting as a single market where, for this purpose, the degree of (external) pluralism is associated with the level of concentration. Instead, the there is some indirect evidence from the influence of cross media ownership and some direct evidence from the beneficial effect of independent regulation of PSB that broadcasting still contributes to media pluralism in a manner that is distinct from that of newsprint through a form of internal pluralism.

From this we conclude that if policy makers and regulators are concerned with media pluralism because it affects citizen knowledge across a range of knowledge categories, then concentration in newsprint should be avoided, concentration in broadcasting is not a problem and independent regulation of PSB is to be preferred.

Of course, there are reasons other than citizen knowledge for valuing pluralism in the media and so these results do not tell whole story about what matters in media pluralism. Nevertheless, they are important in the current policy debate over media 
pluralism where the conventional wisdom often focuses on concentration in ownership (rather than titles) and where the distinction between newsprint and broadcasting is often thought to be fast disappearing (e.g., see OFCOM, 2010).

References:

Berry, S. and J. Waldfogel. 2001. Do mergers increase product variety? Evidence from radio broadcasting. Quarterly Journal of Economics, August: 1009-1025.

Besley, T. and A. Prat. 2006. Handcuffs for the grabbing hand: media capture and government accountability, American Economic Review, 96(30): 720-736.

Betzel, M. 2003. Programme Performance of Public Service Broadcasting and its Mission in the Digital Age. Dusseldorf: European Platform of Regulatory Authority, European Institute for the Media.

Connolly, S. and S. Hargreaves Heap. 2007. Cross country differences in trust in television and the governance of public broadcasters, Kyklos, 60(1): 3-14.

Council of Europe. 2009. Methodology for monitoring media concentration and media content diversity. Strasbourg: DG Human Rights and Legal Affairs.

Curran, J., Iyengar, S., Lund, A.B., and I. Salovaara-Moring. 2009. Media System, Public Knowledge and Democracy: A Comparative Study, European Journal of Communication 24: 5.

De Luca, G. and Magnus, J.R., 2011, Bayesian model averaging and weightedaverage least squares: Equivalence, stability, and numerical issues, The Stata Journal. 11(4): 518-544. 
Djankov, S., C. McLiesh, T. Nenova and A. Shleifer. 2003. Who owns the media?, Journal of Law and Economics. XLVI: 341-380.

Elstein, D. (2011). 'Measuring cross-media ownership', http://stakeholders.ofcom.org.uk/binaries/consultations/measuringplurality/response s/david-elstein.pdf

European Commission. 2007. Media Pluralism in the Member States of the European Union. Brussels

Gentzkow, M and J. Shapiro. 2006. What Drives Media Slant? Evidence from U.S. Daily Newspapers, Journal of Political Economy, 114(2): 280-316.

Hanretty, C. 2012. Public Service Broadcasting's Continued Rude Health. London: British Academy.

Hanretty, C. and C. Koop. 2013. Shall the law set them free? The formal and actual independence of regulatory authorties. Regulation and Governance, 7, 195-214.

Hooghe, L., Marks, J., and Schakel, A. 2010. The Rise of Regional Authority: A Comparative Study of 42 Democracies. London: Routledge.

Kwerel, E., Levy, J., Pepper, R., Sappington, D., Stockdale, D. and Williams, J. 2002. Economic Issues at the Federal Communication Commission, Review of Industrial Organisation, 21, 337-55.

Leeson, P. 2008. 'Media Freedom, Political Knowledge, and Participation' Journal of Economic Perspectives, 22(2): 155-169.

OFCOM. 2010. Report on public interest test on the proposed acquisition of British Sky Broadcasting Group plc by News Corporation. December 2010. London.

OFCOM. 2012. Measuring media plurality, June 2012, London. 
Page, S. 2007. The difference: how the power of diversity creates better groups, firms, schools and societies. Princeton: Princeton University Press.

Pew Center. 2007. 'Public Knowledge of Current Affairs Little Changed by News and Information Revolutions: What Americans Know 1989-2007', people-press org/reports/print.php3?PageID=1137

Prat, A. and D. Strömberg. 2006. 'Commercial Television and Voter Information', LSE working paper.

Soroka, S. 2006. 'Good News and Bad News: Asymmetric Responses to Economic Information', Journal of Politics, 68, 372-85.

Soroka, S., Andrew, B., Aalberg, T., Iynegar, S., Curran, J., Coen, S., Hayashi. K., Jones, P., Mazzoleni, G., Rhee, J., Rowe, D., and Tiffen, R. 2012. 'Auntie Knows Best: public broadcasters and current affairs knowledge', British Journal of Political Science, 43(4): 719-739.

Toka, G. and Popescu, M. 2009. 'Public television, private television and citizens' political knowledge', EUI Working Paper RSCAS 2009/66.

US State Department. 2006. International Religious Freedom Report. Washington D.C. 
Appendix 1: Data sources for Citizen Knowledge

Political knowledge

EES (2009), European Parliament Election Study 2009, Voter Study, Advance

Release, 7/4/2010, (www.piredeu.eu).

There were 3 standardized questions on domestic politics. They ask each respondent to decide whether the following statements are true or false:

- the identity of the Minister for Children (or its analogue in that country) is.....;

- the minimum age for membership of the governing Assembly of that country is.....;

- the number of seats in the governing Assembly for that country is.......

For the UK, in 2009, the correct responses were as follows:

Question 96 - 'The British Secretary of State for Children, schools and families is Ed Balls.'

Question 97 -'Individuals must be 25 or older to stand as candidates in British general elections.'

Question 98 - 'There are 969 members of the British House of Commons'

Economic knowledge - Special Eurobarometer

'Europeans' knowledge of economic indicators'

Fieldwork April-May 2007

Publication April 2008

http://ec.europa.eu/public_opinion/archives/ebs/ebs_special_eco_ind_en.pdf

Growth - pages 14, 17 and 59

A: "What was the official growth rate of the economy (measured in terms of Gross Domestic Product) in (OUR COUNTRY) in 2008? I can tell you that this figure is between $-5 \%$ and $+10 \%$."

B: "In 2007, the official growth rate (measured in terms of Gross Domestic product) in (OUR COUNTRY) was [INSERT THE EXACT RATE OF YOUR COUNTRY]\%. What was the official growth rate of the economy in (OUR COUNTRY) in 2008? I can tell you that this figure is between $-5 \%$ and $+10 \%$."

Inflation - pages 19, 22 and 63

"What was the official inflation rate, the rate of which consumer prices increased or decreased, in (OUR COUNTRY) in 2008? I can tell you that the exact figure is between $-5 \%$ and $20 \%$."

Unemployment - pages 24, 26 and 65

"What was the official unemployment rate, the percentage of active people who do not have a job, in (OUR COUNTRY) in 2008? I can tell you that the exact figure is between $0 \%$ and $20 \%$."

Number of correct answers - page 27

An answer within $\pm 20 \%$ of the official rate were defined as 'correct'. Overall, large proportion do not know or are unwilling to estimate the values of the economic indicators - circa 35\%. Half of those sampled were given the value of growth for 
2007 - they tended to give less accurate estimate than those who were not given this information. Levels of accuracy on growth seemed to have declined but have improved for inflation and unemployment since the previous Eurobarometer survey in 2006.

Scientific knowledge - Special Eurobarometer 224

'Europeans, science and technology'

Fieldwork Jan-Feb 2005

Publication June 2005

http://ec.europa.eu/public_opinion/archives/ebs/ebs_224_report_en.pdf

Knowledge questions - page 40

"The sun goes around the earth; the centre of the earth is very hot; the oxygen we breathe comes from plants; Radioactive milk can be made safe by boiling it; Electrons are smaller than atoms; The continents on which we live have been moving for millions of years and will continue to move in the future; The earliest humans lived at the same time as the dinosaurs; Antibiotics call viruses as well as bacteria; Lasers work by focusing sound waves; All radioactivity is man-made; Human beings, as we know them today, developed from earlier species of animals; It takes one month for the Earth to go around the Sun." T/F

Average of correct answers - page 41

Breakdown of correct answers - pages 209-223

Heard about new developments in science - Special Eurobarometer 341

'Biotechnology'

Fieldwork Jan-Feb 2010

Publication October 2010

http://ec.europa.eu/public_opinion/archives/ebs/ebs_341_en.pdf

GM foods - pages 260-1

Nanotechnology - pages 273-4

Animal cloning - pages 286-7

Synthetic biology - pages 327-8

Biobanks - pages 341-2

"Have you ever heard/talked about (TOPIC) with anyone before today?" Responses: Yes, frequently; Yes, occasionally; Yes, only once or twice; No, never; Don't know. Yes = Yes, frequently; Yes, occasionally; Yes, only once or twice

Climate change - Special Eurobarometer 313

'Europeans' attitude to climate change'

Fieldwork Jan-Feb 2009

Publication July 2009

http://ec.europa.eu/public_opinion/archives/ebs/ebs_313_en.pdf

Personally, do you think that you are well informed or not about the consequences on climate change - pages 22 and 60 
"Personally, do you think that you are well informed or not about the consequences on climate change?" Responses: Very well informed; Fairly well informed; Not very well informed; Not at all informed; Don't know.

Well informed = Very well informed; Fairly well informed

Climate change is an unstoppable process, tend to disagree - pages 35 and 62 "Please tell me whether you personally totally agree, tend to agree, tend to disagree or totally disagree with each of the following statements. Climate change is an unstoppable process, we cannot do anything about it." 
Descriptive Statistics

Political knowledge (\% correct)

Economic knowledge (\% correct)

Scientific knowledge (\% correct)

New developments in technology (\% who have heard)

Well informed about the consequences on climate change ( $\%$ who agree)

HI TV channels

HI Press titles

HI TV broadcasters

HI Press owners

Number TV channels

Number Press titles

Number TV broadcasters

Number newspapers

Freedom House Index

PSB regulatory authority $(1=$ Yes, $0=$ No $)$

PSB ministry $(1=$ Yes, $0=$ No $)$

PSB audience share (\% of total audience)

GDP per capita

$\%$ of population with secondary education

Cross media ownership $(1=$ Yes, $0=$ No $)$

\begin{tabular}{|c|c|c|c|c|}
\hline Minimum & Maximum & Mean & Median & Std. Deviation \\
\hline 36.4 & 77.2 & 55.9 & 56.1 & 9.8 \\
\hline 4.7 & 29.7 & 14.2 & 14.0 & 6.3 \\
\hline 48.0 & 79.0 & 63.5 & 64.0 & 9.1 \\
\hline 33.4 & 70.2 & 51.1 & 50.6 & 8.9 \\
\hline 29.0 & 84.0 & 55.4 & 57.0 & 15.3 \\
\hline 623 & 2769 & 1583 & 1539 & 482 \\
\hline 1119 & 4577 & 1859 & 1749 & 717 \\
\hline 1243 & 3826 & 2161 & 1988 & 664 \\
\hline 1209 & 5144 & 2536 & 2518 & 796 \\
\hline 4.0 & 15.0 & 7.7 & 7.0 & 2.9 \\
\hline 4.0 & 10.0 & 9.0 & 10.0 & 1.8 \\
\hline 3.0 & 10.0 & 5.5 & 5.0 & 2.0 \\
\hline 4.0 & 10.0 & 7.2 & 8.0 & 1.8 \\
\hline 9.0 & 42.0 & 19.3 & 19.0 & 7.3 \\
\hline 0.00 & 1.00 & 0.48 & 0.00 & 0.51 \\
\hline 0.00 & 1.00 & 0.30 & 0.00 & 0.47 \\
\hline 13.1 & 69.1 & 35.4 & 36.8 & 14.1 \\
\hline 10491 & 75337 & 27818 & 27167 & 12835 \\
\hline 26 & 90 & 72 & 76 & 17 \\
\hline 0.00 & 1.00 & 0.52 & 1.00 & 0.51 \\
\hline
\end{tabular}


EU East

EU South

Index of regional governance

Average rate of growth 2001-06

Average rate of inflation 2001-06

Average rate of unemployment 2001-06

Tertiary graduates in science and technology

Green House Gas Emissions per capita

$\begin{array}{ccccc}0.00 & 1.00 & 0.37 & 0.00 & 0.49 \\ 0.00 & 1.00 & 0.22 & 0.00 & 0.42 \\ 0.0 & 29.4 & 9.0 & 7.1 & 8.6 \\ 0.9 & 8.9 & 3.8 & 3.6 & 2.1 \\ 1.8 & 20.7 & 4.0 & 3.2 & 3.7 \\ 3.3 & 16.5 & 7.6 & 7.3 & 3.3 \\ 2.5 & 21.6 & 11.5 & 10.7 & 4.8 \\ 0.0047 & 0.0263 & 0.0111 & 0.0101 & 0.0042\end{array}$

